\title{
Wrist deformity, bother and function following wrist fracture in the elderly
}

\author{
Andrew Lawson ${ }^{1 *}$, Partiban Santhakumar ${ }^{1}$, Justine M. Naylor ${ }^{1}$, Tim Churches ${ }^{2}$, Steve Frost ${ }^{3,4}$ and lan A. Harris
}

\begin{abstract}
Objective: Wrist deformity in older people is common following treatment for a wrist fracture, particularly after nonsurgical treatment. A cohort of older wrist fracture patients were surveyed by telephone regarding perceived deformity, bother with deformity and patient-reported wrist function. The objectives were to: (1) determine whether older patients with wrist fractures perceived a deformity of their wrist and if they were bothered by it; (2) test if there were associations between deformity and treatment-type and between deformity and function; (3) test for associations between bother and treatment-type and between bother and function; (4) measure the test-retest reliability of the 'bother' question.

Results: Of 98 eligible patients who were invited to participate, 41 responded. Out of 41, 14 (34\%) believed they had a deformity and $4(10 \%)$ reported that they were bothered by the appearance of their wrist. Deformity was associated with non-surgical treatment $(R R=3.85, p=0.006)$ but was not significantly associated with functional outcomes $(p=0.15)$. All those who were bothered belonged to the non-surgical treatment group. Bother was significantly associated with poorer functional outcomes $(p=0.006)$ and this association was clinically significant $(M D=35$ points). The deformity and bother questions were found to have excellent test-retest reliability; $k=1.00$ and $k=0.92$, respectively.

Keywords: Bother, Wrist, Conservative treatment, Deformity, Fracture fixation, Patient reported outcome, Distal radius fracture
\end{abstract}

\section{Introduction}

Wrist fractures are common in people aged 50 and over. Wrist fractures are associated with female gender, simple falls and osteoporosis [1-3]. Wrist fractures account for $18 \%$ of all fracture types in the elderly (65 years and over) [4]. The two most common forms of treatment for wrist fractures in older patients are non-surgical treatment (closed reduction and plaster immobilization) and surgical fixation using a volar locking plate [5, 6]. Traditionally, in older patients, wrist fractures were most commonly managed by non-surgical treatment. However, there has been a shift towards surgical treatment (particularly volar

\footnotetext{
*Correspondence: aalawson@tpg.com.au

${ }^{1}$ Whitlam Orthopaedic Research Centre, Ingham Institute for Applied Medical Research, South Western Sydney Clinical School, UNSW, Sydney, NSW, Australia

Full list of author information is available at the end of the article
}

locking plate fixation) with a fivefold increase in the past 20 years [5]. The main reason for the use of surgical fixation is to maintain better fracture alignment. A survey of orthopaedic surgeons in Australia who were presented with a case of a typical wrist fracture sustained by a 75-year-old female revealed stronger preference for surgical fixation using volar locking plates (47\%) compared with closed reduction with cast immobilisation (23\%) [7].

Malunion is a common complication following nonsurgical treatment of wrist fractures. Estimates of rates of malunion associated with closed reduction and cast fixation of wrist fractures have been reported as high as $50 \%[1,2]$. Symptomatic deformity can be treated using surgery [8]. However, malunion and the presence of deformity are usually well-tolerated and deformity isn't necessarily associated with poor functional outcomes. In fact, studies comparing functional outcomes with radiographic outcomes in the medium and long-term

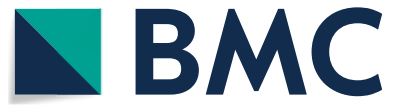

(c) The Author(s) 2020. This article is licensed under a Creative Commons Attribution 4.0 International License, which permits use, sharing, adaptation, distribution and reproduction in any medium or format, as long as you give appropriate credit to the original author(s) and the source, provide a link to the Creative Commons licence, and indicate if changes were made. The images or other third party material in this article are included in the article's Creative Commons licence, unless indicated otherwise in a credit line to the material. If material is not included in the article's Creative Commons licence and your intended use is not permitted by statutory regulation or exceeds the permitted use, you will need to obtain permission directly from the copyright holder. To view a copy of this licence, visit http://creativeco mmons.org/licenses/by/4.0/. The Creative Commons Public Domain Dedication waiver (http://creativecommons.org/publicdomain/ zero/1.0/) applies to the data made available in this article, unless otherwise stated in a credit line to the data. 
following treatment for wrist fracture have shown little if any agreement [9-11]. Despite the higher rates of malunion and deformity associated with closed reduction, trials comparing surgical and non-surgical treatment of wrist fractures in elderly patient populations have demonstrated that satisfactory functional outcomes can still be achieved with non-surgical treatment $[1,12,13]$.

Understanding the degree to which patients experience and are bothered by wrist deformity following the treatment of their fractured wrist would assist in clinical decision making for this common fracture. The aims of this retrospective study were fourfold. We aimed to investigate:

1. Incidence of perceived deformity and bother and their association.

2. Association between perceived deformity, and treatment and function.

3. Association between bother, and treatment and function.

4. Test-retest reliability of deformity and bother questions.

\section{Main text \\ Methods \\ Patient population and screening}

The patient population were elderly people who had presented to our institution over a 5-year period with a wrist fracture. Eligible people were identified from an electronic orthopaedic database. Inclusion criteria were: age 65 years and over; treatment of their fracture either by closed reduction and cast immobilization or by open reduction and plate fixation. Exclusion criteria included residency in a nursing home and inability to provide informed consent (e.g. those patients with documented dementia or those with low English proficiency).

Potentially eligible participants were sent a letter informing them of the study (Additional file 1: Appendix S1) and providing them with the opportunity to opt out by contacting the research department. After 2-3 weeks, a follow-up telephone call was made to eligible participants who had not opted out. Efforts were made to contact the entire cohort. If a telephone number could not be found, then a second letter was sent to the eligible participant inviting them to contact the research institute if they were interested in participating in the study.

Those agreeing to participate provided consent and the survey was conducted over the telephone by a researcher (PS).

\section{Outcome measures}

The telephone survey (Additional file 2: Appendix S2) was made up of two parts. The first part of the survey was designed to assess patient-perceived deformity and bother. Firstly, participants were asked whether they believed that they had a deformity in the affected wrist using a simple dichotomous question; "Do you consider your wrist to be deformed or crooked?" Secondly, participants were asked about the extent to which they were bothered by the appearance of their wrist on a 5-point Likert scale (1-Not at all, 2-A little, 3Moderately, 4-Very, 5-Extremely). The format of the bother question was based on the format of questions that make up the bother index in the short musculoskeletal function assessment (SMFA) questionnaire. The SMFA has been assessed as being a reliable and valid tool for use in musculoskeletal disease or injury [14].

The second part of the survey consisted of the PatientRated Wrist Evaluation (PRWE) questionnaire. The PRWE is a common and validated measure that is used to assess the pain and function of a patient following a wrist injury [15]. The PRWE is made up of two sections assessing pain and function. The sum of both the pain and function sections produces a single score out of 100 [16], with 0 representing no wrist pain and disability and 100 representing maximum wrist pain and disability. The minimum clinically important difference (MCID) for PRWE scores for wrist fracture patients has been reported as 11.5 points [17].

To assess the reliability of the deformity and the bother questions, participants were asked for their consent to be followed up 1 week after the initial phone interview to be asked the two questions again. The aim of this was to assess the test-retest reliability of these two questions. See Additional file 1: Appendix S1 for entire telephone script including the survey questions.

\section{Statistical analysis}

Results were analysed using R-statistical language [18].

Relative risk ratios (RR) and p-values were reported for perceived deformity by treatment-type and for perceived deformity vs bother.

As an indication of wrist function, PRWE scores were calculated. Medians and interquartile ranges of PRWE results were reported, according to associations with treatment-type, perceived deformity and perceived bother. Statistical significance was measured using chi squared tests and Mann-Whitney Wilcoxon tests $(U)$. Means of functional scores were compared between groups using one-way analysis of Variance (ANOVA). Results were statistically significant when $\mathrm{p}<0.05$. 
The test-retest reliability of the deformity and bother questions was analysed using Cohen's Kappa. Kappa scores between 0.75 and 1.00 were considered to be excellent [19].

\section{Results \\ Cohort ascertainment}

From 1165 recorded cases of wrist fracture presenting between January 2010 and December 2014, there were 98 potentially eligible participants. 9 opted out and 89 eligible patients were contacted by telephone. From these, 41 consented to undertake the initial survey and 27 of these consented to repeating the survey 1-week later. A profile of the study participants is described in Additional file 3 and the participant flow is displayed in Fig. 1. Participant characteristics were similar to the cohort with regard to age, treatment-type and injured side (left or right). There was a low participation rate of males compared with the cohort.

\section{Incidence of perceived deformity and bother}

Of 41 participants, 14 (34\%) perceived that they had a wrist deformity and $4(10 \%)$ reported that they were bothered by the appearance of their wrist. Three of these four perceived that they had a wrist deformity. Interestingly, one participant who did not perceive a deformity reported that he or she was bothered by the appearance of his or her wrist. Additional file 4 displays a comparison of the perception of bother (dichotomous; yes/no) with the perception of deformity (yes/no). Those who perceived that they had a deformed wrist were more likely to be bothered by the appearance of it than those who perceived no deformity (RR 5.79, $\mathrm{p}=0.07$ ).

\section{Association between perceived deformity and treatment-type/function}

In the non-surgical treatment group, 11 out of 20 patients (55\%) perceived deformity and in the surgical treatment group, only 3 out of 21 patients (14\%) believed that their wrist was deformed. Participants treated non-surgically

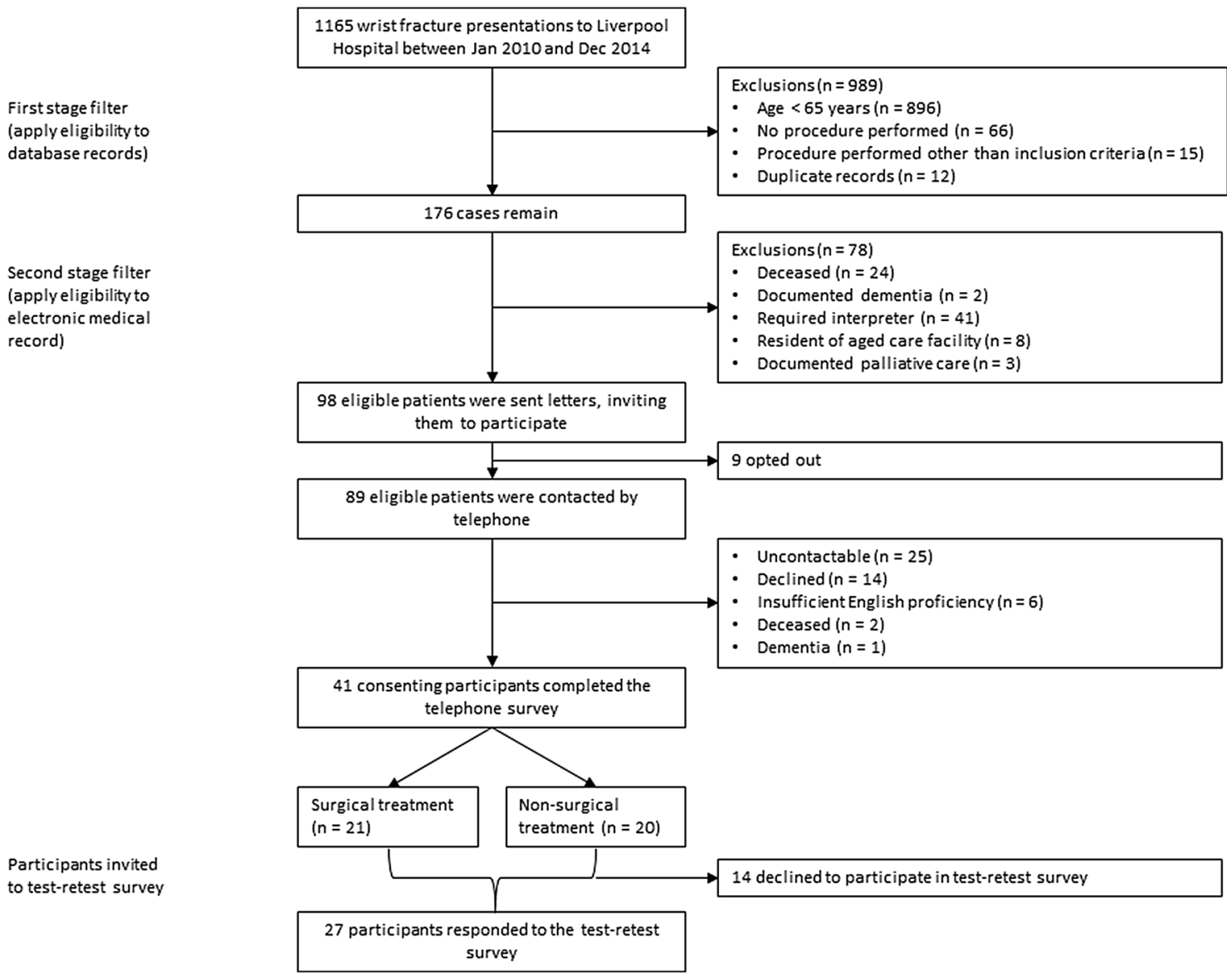

Fig. 1 Flowchart of inclusion of participating patients 


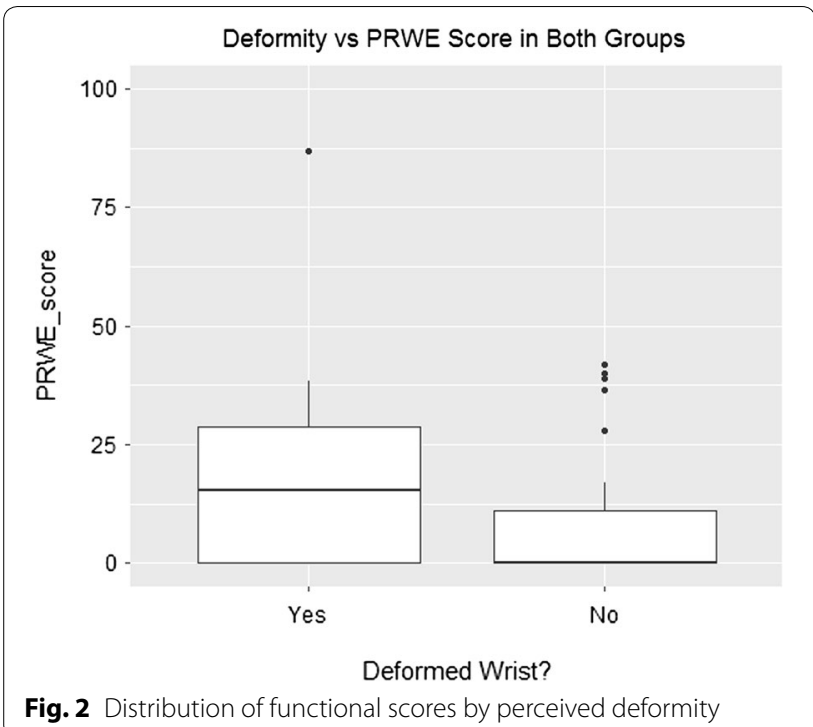

Fig. 2 Distribution of functional scores by perceived deformity

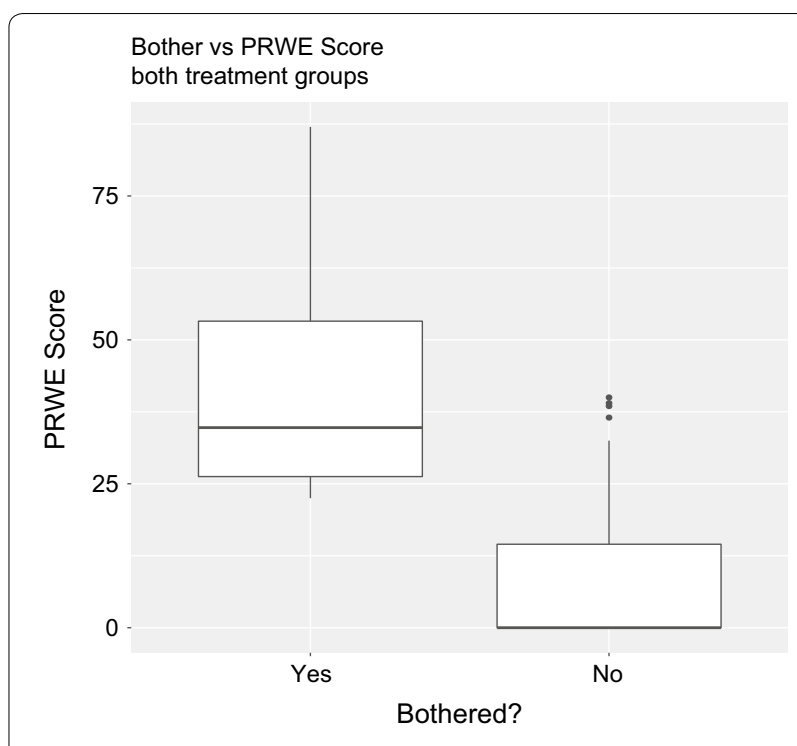

Fig. 3 Distribution of functional scores by reported bother (yes/no)

(Additional file 9). For the bother question, 26 participants provided the same answer week-to-week and one changed their answer from a little bothered to not at all bothered. The reliability of the bother question at $\mathrm{k}=0.92$ represented "excellent agreement".

\section{Discussion}

The existing evidence concerning wrist deformity following treatment of wrist fractures suggests that deformity is common and that patients are not troubled or bothered by the deformity: A 2005 review of the predictors of patient satisfaction following treatment for wrist fracture concluded that satisfaction was associated with pain relief and grip strength rather than the radiographic findings [20]. A 2011 randomised controlled trial [12] comparing surgical and non-surgical treatment of wrist fractures collected deformity and bother as outcomes but the results were not presented in the report. A 2000 retrospective study on wrist fractures in older patients reported that despite obvious clinical deformity in half of their cohort (14/25), none were "dissatisfied" with the appearance of their wrist [21].

The study most comparable to the current study was a 2009 study of patients over 70 years of age who had undergone surgical or non-surgical treatment for an unstable wrist fracture. That study found that none of the surgical patients had a deformity and that $77 \%$ of nonsurgical patients had a visual deformity [22]. However, the authors reported that no participant was "dissatisfied with the clinical appearance" of their wrist. In comparison, we found a lower rate of deformity (14/41) and we found that some patients with perceived deformity were 
bothered by it (4/41). The difference is likely explained in that our study used patient-reported deformity rather than therapist-assessed deformity.

\section{Limitations}

This study had a few limitations. Primarily, the sample was small potentially limiting the ability to detect statistically significant small differences, and the response rate was low limiting the generalizability of our findings. The study used a convenience sample which was small because the inclusion criteria (treatment-type and age range) were narrow. There were 98 eligible patients but our response rate yielded a sample of only 41 . To be able to observe the effect that we observed in function by perceived deformity to a level of significance, we would need a sample size of over 40 in each treatment group. Also, the bother question was designed as a Likert scale but given that only four participants reported that they were bothered by the appearance of their wrist, the Likert format added little information to the dichotomous format. In a larger cohort, the Likert format may have proved meaningful in informing the extent of bother.

Further, the study was retrospective. As such, the treatment-type was not controlled and the time to follow-up ranged between 2 and 5 years. This created a potential for indication bias relating to the comparisons made between treatment groups.

Finally, the mode of administration may be a limitation. Telephone administration of the survey by an investigator helped ensure the completeness and accuracy of data collected. However, it also created the potential for observer bias. This potential was minimized by using a telephone script (see Additional file 1: Appendix S1).

\section{Supplementary information}

Supplementary information accompanies this paper at https://doi. org/10.1186/s13104-020-05013-5.

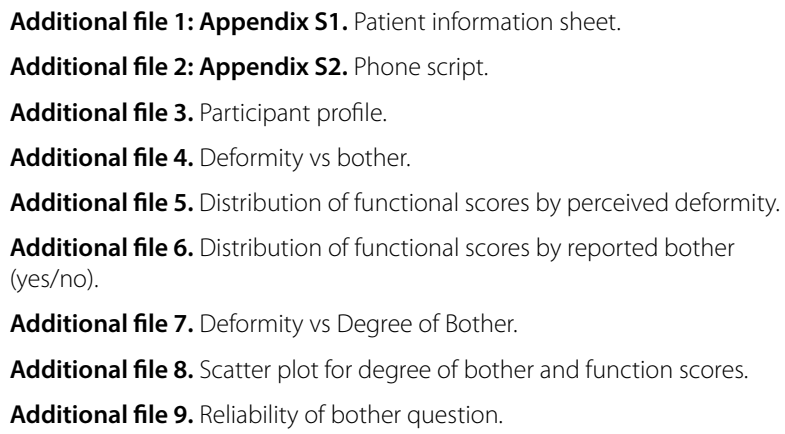

\section{Abbreviations}

ANOVA: Analysis of variance; MCID: Minimal clinically important difference; MD: Mean difference; PRWE: Patient-rated wrist evaluation; RR: Risk ratio; SMFA: Short musculoskeletal function assessment.
Acknowledgements Not applicable.

Previous communication

This work has not been presented elsewhere.

\section{Authors' contributions}

$I H, J N, T C, A L$ and PS contributed to the planning of this study. TC and SF provided advice on data analysis. All authors read and approved the final manuscript.

\section{Funding}

This research received no external funding.

\section{Availability of data and materials}

The datasets used and/or analysed during the current study are available from the corresponding author on reasonable request.

\section{Ethics approval and consent to participate}

Ethics approval was granted by the South Western Sydney Local Health District Human Research Ethics Committee (LNR/16/LPOOL/104).All eligible patients were sent a patient information sheet by mail (Additional file 1: Appendix S1). The patient information sheet informed patients of the nature of the study, that they would be contacted by telephone in 2 weeks time and that they could opt out of being contacted. Patients who did not opt out were contacted by telephone. Participants provided informed consent verbally over the telephone.

\section{Consent for publication}

Not applicable.

\section{Competing interests}

The authors declare that they have no competing interests.

\section{Author details}

${ }^{1}$ Whitlam Orthopaedic Research Centre, Ingham Institute for Applied Medical Research, South Western Sydney Clinical School, UNSW, Sydney, NSW, Australia. ${ }^{2}$ Ingham Institute for Applied Medical Research, South Western Sydney Clinical School, UNSW, Sydney, NSW, Australia. ${ }^{3}$ Centre for Applied Nursing Research, Ingham Institute of Applied Medical Research, Sydney, NSW Australia. ${ }^{4}$ South Western Sydney Local Health District (SWSLHD), Sydney, NSW, Australia.

Received: 2 February 2020 Accepted: 11 March 2020

Published online: 20 March 2020

\section{References}

1. Diaz-Garcia RJ, Oda T, Shauver MJ, Chung KC. A systematic review of outcomes and complications of treating unstable distal radius fractures in the elderly. J Hand Surg Am. 2011;36(5):824-835.e822.

2. Boufous S, Finch CF, Lord SR. Incidence of hip fracture in New South Wales: are our efforts having an effect? Med J Aust. 2004;180:623-6.

3. Baron JA, Karagas M, Barrett J, et al. Basic epidemiology of fractures of the upper and lower limb among Americans over 65 years of age. Epidemiology. 1996;7:612-8.

4. Nellans KW, Kowalski E, Chung KC. The epidemiology of distal radius fractures. Hand Clin. 2012;28(2):113-25.

5. Chung KC, Shauver MJ, Birkmeyer JD. Trends in the United States in the treatment of distal radial fractures in the elderly. J Bone Joint Surg Am. 2009;91(8):1868-73

6. Mauck BM, Swigler CW. Evidence-based review of distal radius fractures Orthop Clin North Am. 2018:49(2):211-22.

7. Ansari U, Adie S, Harris IA, Naylor JM. Practice variation in common fracture presentations: a survey of orthopaedic surgeons. Injury. 2011:42:403-7

8. Jupiter JB, Fernandez DL. Complications following distal radial fractures. J Bone Joint Surg Am. 2001;83:1244-65. 
9. Kopylov P, Johnell O, Redlund-Johnell I, et al. Fractures of the distal end of the radius in young adults: a 30-year follow-up. J Hand Surg Br. 1993;18(1):45-9.

10. Forward DP, Davis TR, Sithole JS. Do young patients with malunited fractures of the distal radius inevitably develop symptomatic post-traumatic osteoarthritis. J Bone Joint Surg Br. 2008;90:629-37.

11. Plant CE, Parsons NR, Costa ML. Do radiological and functional outcomes correlate for fractures of the distal radius? Bone Joint J. 2017;99-b(3):376-82.

12. Arora R, Lutz M, Deml C, et al. A prospective randomized trial comparing nonoperative treatment with volar locking plate fixation for displaced and unstable distal radial fractures in patients sixty-five years of age and older. J Bone Joint Surg Am. 2011;93:2146-53.

13. Bartl C, Stengel D, Bruckner T, Gebhard F, ORCHID Study Group. The treatment of displaced intra-articular distal radius fractures in elderly patients. Dtsch Arztebl Int. 2014;111(46):779-87.

14. Swiontkowski MF, Engelberg R, Martin DP, Agel J. Short musculoskeletal function assessment questionnaire: validity, reliability, and responsiveness. J Bone Joint Surg Am. 1999;81(9):1245-60.

15. Kleinlugtenbelt YV, Nienhuis RW, Bhandari M, Goslings JC, Poolman RW, Scholtes VA. Are validated outcome measures used in distal radial fractures truly valid? A critical assessment using the COnsensus-based Standards for the selection of health Measurement INstruments (COSMIN) checklist. Bone Joint Res. 2018;7(1):36-45.

16. The Patient-Rated Wrist Evaluation (PRWE) User Manual, June 2011. https ://srs-mcmaster.ca/wp-content/uploads/2015/05/English-PRWE-UserManual.pdf, Accessed 20 Oct 2018.
17. Walenkamp MM, de Muinck Keizer RJ, Goslings JC, Vos LM, Rosenwasser MP, Schep NW. The minimum clinically important difference of the patient-rated wrist evaluation score for patients with distal radius fractures. Clin Orthop Relat Res. 2015;473(10):3235-41.

18. R Core Team. R: a language and environment for statistical computing. Vienna: R Core Team; 2018.

19. Cicchetti DV. Guidelines, criteria, and rules of thumb for evaluating normed and standardized assessment instruments in psychology. Psychol Assess. 1994:6(4):284-90.

20. Slutsky DJ. Predicting the outcome of distal radius fractures. Hand Clin. 2005;21(03):289-94.

21. Young BT, Rayan GM. Outcome following nonoperative treatment of displaced distal radius fractures in low-demand patients older than 60 years. J Hand Surg. 2000;25(1):19-28.

22. Arora R, Gabl M, Gschwentner M, Deml C, Krappinger D, Lutz M. A comparative study of clinical and radiologic outcomes of unstable colles type distal radius fractures in patients older than 70 years: nonoperative treatment versus volar locking plating. J Orthop Trauma. 2009;23:237-42.

\section{Publisher's Note}

Springer Nature remains neutral with regard to jurisdictional claims in published maps and institutional affiliations.
Ready to submit your research? Choose BMC and benefit from:

- fast, convenient online submission

- thorough peer review by experienced researchers in your field

- rapid publication on acceptance

- support for research data, including large and complex data types

- gold Open Access which fosters wider collaboration and increased citations

- maximum visibility for your research: over $100 \mathrm{M}$ website views per year

At BMC, research is always in progress.

Learn more biomedcentral.com/submissions 